
fertility. Journal of Education, Health and Sport. 2020;10(9):216-227. eISSN 2391-8306. DOI http://dx.doi.org/10.12775/JEHS.2020.10.09.023

https://apcz.umk.pl/czasopisma/index.php/JEHS/article/view/JEHS.2020.10.09.023

https://zenodo.org/record/4019655

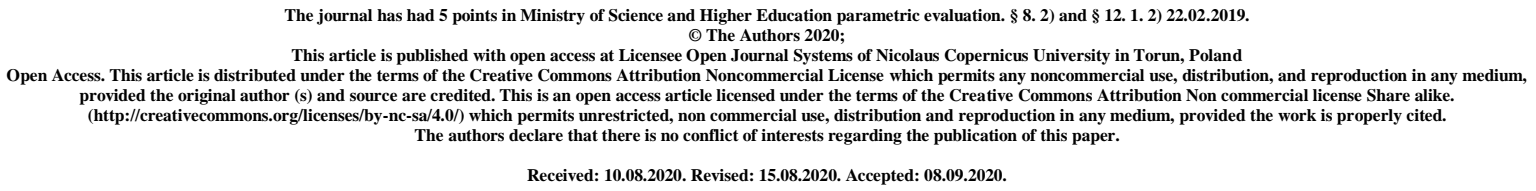

\title{
An impact of selected micronutrients on fertility
}

Klaudia Żak, e-mail: zakklaudia3@ gmail.com, ORCID : https://orcid.org/0000-0003-2421$2553(1)$

Milena Leziak, e-mail: milena.leziak@wp.pl, ORCID: https://orcid.org/0000-0001-9911$5534(1)$

Sylwiusz Niedobylski, e-mail: sniedobylski@gmail.com, ORCID : https://orcid.org/00000001-7266-623X (1),

Michal Piwoński, e-mail: michalpiwonski2@gmail.com, ORCID: https://orcid.org/00000001-6510-8993 (1)

Katarzyna Laszczak; e-mail: kasia.laszczak19@gmail.com, ORCID: https://orcid.org/00000002-5084-0273 (1);

1 - Medical University of Lublin 


\begin{abstract}
Introduction and purpose: The problem with infertility affects between 8 and 12\% of reproductive-aged couples. Among the reasons, smoking, adulterated food, hormonal disorder are featured. Our purpose is to check how micronutrients impact fertility.
\end{abstract}

Brief description of the state of knowledge: Micronutrients deficiency, specifically zinc and selenium deficiencies have also unpropitious impact on fertility. In this review, the potential role of these microelements in male and female reproductive health is considered. Zinc had been proved to regulate sperm motility, spermatogenesis and reduce oxidative stress. Lower delivery of selenium decrease testosterone level by causing changes in receptor of the luteinising hormone. It is also compared with lower spermatozoa concentration. In this review the role of iron, manganese, lead, nickel, copper, magnesium and cobalt is described as well.

Summary: Deficiencies of some micronutrients may make worse the fertility. That's the reason why additional supplementation may be important in the treatment of infertility.

Key words: fertility; micronutrients; microelements; zinc; selenium

\title{
Introduction and purpose
}

Fertility is certainly an important issue for everyone who wants to have a baby. A lot of people are afraid of being infertile especially while hearing in media about "remarkable" decline in fertility rate. Infertility can lead to distress and depression, as well as discrimination and ostracism [1].

World Health Organization defines infertility as "a disease of the reproductive system defined by the failure to achieve a clinical pregnancy after 12 months or more of regular unprotected sexual intercourse"[2]. Primary infertility refers to the inability to give birth either because of not being able to become pregnant, or carry a child to live birth, which may include miscarriage or a stillborn child. Secondary infertility refers to the inability to conceive or give birth when there was a previous pregnancy or live birth [3]. In developing countries primary infertility is more common.

It is estimated that infertility affects between 8 and $12 \%$ of reproductive-aged couples worldwide [4]. According the World Health Organization, about 60-80 million couples are permanently or periodically affected by infertility. Male infertility is responsible for $20-30 \%$ of infertility cases, while $20-35 \%$ are due to female infertility, and $25-40 \%$ are due to combined problems in both parts [5]. In 10-20\% of cases, no cause is found. It is hard to tell whether fertility rate increase or decrease over the past few years. Many retrospective studies suggest that there has been a decrease in semen quality over the past several decades in different countries throughout the world [6].

The occurrence of infertility in Poland is not fully recognized due to the lack of current and complete statistical data. It is estimated that the scale of this phenomenon is similar to that in highly developed countries. About 3 million people in Poland are affected by infertility. In 2010 Poland was one of the countries with the lowest estimated prevalences of primary infertility [1]. 
When it comes to infertility in men, more than $90 \%$ of cases are due to low sperm counts, poor sperm quality or both. Other causes include anatomical problems, hormonal imbalances and genetic defects. Treatment depends on why and what is causing the problem, so there is a variety of options. Improving quality of sperm: adopting lifestyle changes (reducing smoking, wearing loose clothing, reducing drug consumption and weight loss) may help. Good nutrition is also important to help improve the quality of the sperm and sperm production [7]. Abnormalities of sperm may be treated with gonadotropin therapy, intrauterine insemination, or in vitro fertilization [8]. There are also surgical procedures: transurethral resection of the ejaculatory ducts (TURED), vasovasostomy and tubulovastomy.

When it comes to women's infertility there is no method to reverse advanced maternal age, but there are assisted reproductive technologies for many causes of infertility in premenopausal women including ovulation induction or in vitro fertilization.

There has been increasing interest in the effects of diet, lifestyle, and environmental exposures on reproductive potential [6]. A healthy diet may increase fertility in men and women who have had no diagnosed problems with fertility, but for people who already have some, the diet may not be enough. In this article, some diet elements were chosen and analysed in terms of how they may influence fertility.

Our purpose is to check how micronutrients impact fertility.

\section{The state of knowledge}

\section{Zinc (Zn)}

Zinc ( $\mathrm{Zn})$ has great impact on reproduction in males and females [9] .Through recent years it had been proven that low doses of $\mathrm{Zn}$ are essential for germ cells, progression of spermatogenesis [10], and regulation of sperm motility [11]. There are two main groups of Zn transporters that include: Zinc -importer (Zip1-14), which transport Zn into cytosol and Zn transporter (ZnT1-10) that remove Zn from a cell [12].

Table 1. Zn receptors necessary for spermatogenesis. [13]

\begin{tabular}{|c|c|c|}
\hline $\begin{array}{l}\text { Zinc } \\
\text { receptors }\end{array}$ & Localization & Role in $\mathrm{Zn}$ circulation \\
\hline Zip5 & $\begin{array}{l}\text { Plasma membrane of Sertoli cells, } \\
\text { primary and secondary spermatocytes }\end{array}$ & $\begin{array}{l}\text { Acquisition from circulation, providing } \\
\text { spermatocytes with } \mathrm{Zn}\end{array}$ \\
\hline ZnT1 & Sertoli cells & Export to developing germ cells \\
\hline Zip14 & $\begin{array}{l}\text { Spermatogonium, Leydig cells } \\
\text { membrane }\end{array}$ & Providing $\mathrm{Zn}$ for testosterone synthesis \\
\hline Zip1 & Elongating spermatids & $\begin{array}{l}\text { Possibility of } \mathrm{Zn} \text { import from prostatic } \\
\text { fluid for viability and motility during } \\
\text { spermatozoa ejaculation }\end{array}$ \\
\hline
\end{tabular}


The most $\mathrm{Zn}$ concentration had been observed in mitochondria of spermatogonia, spermatids and spermatozoa. [14]

In the mice xenografts, the ZnT7 gene in Leydig tumor cell line (MLTC-1 cell line) was silenced. Therefore, the strong decrease of steroidogenic acute regulatory protein (StAR) was observed. StAR is the transporter of cholesterol into Leydig mitochondria, so that it resulted in malfunctioning levels of testosterone. [15] The other study lead to the conclusion that displacement of Zn through ZnT8 cause phosphorylation of StAR, increasing its activity. [16]

Zinc finger protein factor (ZNF) group mostly affect cell cycle. ZNF185, also known as ZPF185 shows strong correlation with Leydig cells, Sertoli cells and sperm. The Leydig cells were obtained from rats. The lentiviral mediated RNA interference was used to inhibit ZNF185 effect. According to that quantity of testosterone diminish, that again shows high connection between zinc and testosterone. [17]

Another Zn finger ZFP318, during spermatogenesis process is primary expressed in spermatocytes and then in seminiferous tubules. It mostly affect meiosis in spermatogenesis and it's defect leads to the lower number of haploid germ cells as well as malformations of nuclei in seminiferous epithelium. [18]

Zn deficiency not only concern testosterone, but all steroid hormones. It is associated with decrease level of progesterone and increase in luteinizing hormone (LH) and folliclestimulating hormone (FSH). It also cause apoptosis of Leydig cells which has high impact on testosterone production. [19] Studies on animals showed that there is clear correlation between $\mathrm{Zn}$ and testosterone metabolism, however exact process stay unclear. [15]

$\mathrm{Zn}$ is also component of many enzymes involved in preventing from oxidative stress. [20] The study was conducted on rats that received doxorubicin (DOX), which is anthracycline antibiotic that can cause cytotoxic effect due to increased number of quinone type three radicals. It showed that animals treated with DOX and $\mathrm{Zn}$ avoided DNA destruction as well as rise of reactive oxygen species. [21] $\mathrm{Zn}$ deficit lead to higher level of 8-oxo-2'deoxyguanosine (8-OHdG) in testes DNA. 8-OHdG is the DNA-repair product, wherefore the higher level of oxidative damage can be seen. [22,23]

Many studies provide us with information about high effect of $\mathrm{Zn}$ in connection with man fertility. Turk et al. [24] examine 143 men, with inflammation process in their semen, expressed prostatic secretion (EPS) and post-prostate-massage urine (post-M). Sterile man with inflammation in genital track occurred to have lower level of zinc (selenium and antioxidants). Wdowiak et al. [25] came up with similar conclusion in study conducted on fertile and infertile male patient in which the higher number of $\mathrm{Zn}$ in the semen of the first group compering to the second one was confirmed. Other study, conducted by Camejo et al. [26] on normozoospermic man and those who had varicocele, showed that higher doses of zinc can positively affect sperm concentration. According to Alsalman [27] et al. the sperm motility, sperm count and volume of semen increase after $\mathrm{Zn}$ completion in asthenospermic patients. Ajina et al. [28] carried on the research in which sperm of 29 asthenoteratozoosperic and 9 isolated asthenozoospermic patients was incubated in vitro with and without $\mathrm{Zn}$. 
What turned out was a higher total antioxidation status in specimen with zinc. Liu et al. [29] in randomised trial choose 67 man with isolated hypogonadotropic hypogonadism (IHH) who fulfil inclusion criteria - age between 18 and 45, without abrupt puberty, with serum testosterone level under $100 \mathrm{ng} \mathrm{dl-1}$ as well as low or normal gonadotrophins and normal testing of the anterior pituitary gland. Selected patients were divided to two groups both on sequential uFSH regimen. One of them went under additional Zinc supplementation. In contrary, the study showed that there was not a significant difference between two groups. Neither testosterone synthesis nor sperm motility increased. However earlier onset of spermatogenesis had been noted in the $\mathrm{Zn}$ supplementation. The semen analysis of subfertile man - Raigani et al. [30] - showed that only combined therapy of $\mathrm{Zn}$ with folic acid rise spermatogenesis (sperm concentration). In recent years plenty meta-analysis were conducted. Taravati et al. [31] admit that there are huge differences between available articles, however the assumption that $\mathrm{Zn}$ concentration is not combined with asthenozoospermia is more probable. Wherefore more study must be provided. Sun et al. [32] investigated 20 casecontrol studies which examine different heavy metal (including $\mathrm{Zn}$ ) effect on fertile semen. The research command that in fertile sperm the number of Zn stay higher, than in infertile one. In current year the another meta-analysis was carried on by Buhling et al. [33]. It showed that semen concentration in patients who supplemented $\mathrm{Zn}$ with folic acid averagely raised from 7,5 to $12,5 \times 10^{\wedge} 6 / \mathrm{ml}$.

Though zinc effect on reproductive system is one of the most examined from all trace elements, more studies must be conducted, as it's the exact action stay unclear.

\section{Selenium (Se)}

Selenium (Se) plays an important role in humans' and other mammals' reproductive system. In some animals even minor, minutes-lasting fluctuations of that element level may negatively affect the reproduction performence [34]. It's a crucial microelement and is a part of many mammalian enzymes associated with fertility and other physiological functions - it's a component of - among others - glutathione peroxidase [35] and testicular selenoproteins [table 2].

Table 2. Selenoproteins associated with reproduction found in testis.

\begin{tabular}{c|cc} 
Selenoprotein & Function & References \\
\hline GPx1 & Antioxidation & {$[36]$} \\
GPx3 & Epithelium protection & {$[36]$} \\
GPx5 & Antioxidation & {$[37]$} \\
cGPx4 & Antioxidation & {$[38]$} \\
Plasma selenoprotein $P$ & Selenium transport to testis & {$[39]$} \\
ApoER2 & Regulation of other selenoproteins & {$[39]$}
\end{tabular}


Contrary to what it may seem, those selenoproteins' function isn't limited to antioxidation and protection exclusively. Protein cGPx4 for instance in later stages of spermatogenesis is transformed into a structural protein that is a part of mitochondrial membrane of spermatozoa [40]. Aside from that, given the fact that elevated reactive oxygen species are found in 30$80 \%$ of infertile men [41] the correlation with selenoproteins' antioxidative properties may be considered. Se has been found to largely influence testicular morphology [42], [43] and it's deficiency to inhibit testis growth and puberty in animals, especially in second and following deficient generations. Histological examination found significant atrophy of microstructures, reduced spermatogenic activity was reported as well [42]. Several genetic knock-out studies of those proteins were conducted which showed that their absence caused deformation of spermatozoa [39], [44], [45], chromatin defects [46], and miscarriages [4], [47] in rats. Lower delivery of selenium may negatively affect the biosynthesis and secretion of testosterone directly or indirectly by causing changes in receptor of the luteinising hormone (LH) as well. [48-50].

Some studies found that correct seminal and/or serum concentractions of Se strongly correlated with correct seminal parameters and higher fertility. Camejo et al. [51] researched patients with decreased seminal parameters due to variocele. Lower seminal levels of selenium turned out to be associated with lower spermatozoa concentration as well as their more faulty morphology and motility. A randomised clinical trial by Ardestani Zadeh et al. [52] showed similar results. 64 infertile subject underwent variocelectomy, after which 30 of them were supplemented with selenium (as well as with vitamin e and folic acid). The group that received the supplementation had significantly higher sperm count and motility after six months of treatment comparing to the control group. Another study on 64 variocele patients by Pajovic et al. [53] focused on veryfing spermatozoa cellular membrane physical integrity using hypo-osmotic swelling test (HOS). The cells' integrity turned out to be directly proportional with selenium concentration. In a case-control study by Eroglu et al. [54] 44 idiopathicly infertile male patients along with 15 healthy subjects had their seminal and serum parameters measured. Both serum and seminal levels of Se were found to be positively correlated with sperm morphology, concentration and motility. Similar results were found in the case control study by Chinyere Nsonwu-Anyanwu et al. [55] and in study by Marzec - Wróblewska et al. [56] - lower sperm concentrations of selenium was associated with worse sperm parameters.

Selenium can play an important role even in preservation of semen. Ghafarizadeh et al. [57] collected semen samples from 50 asthenoteratozoospermic men, then samples were divided to the control and the test group which was incubated with $2 \mu \mathrm{g} / \mathrm{ml}$ selenium at $37^{\circ} \mathrm{C}$. After 2, 4 and 6 hours of incubation the samples were compared. The results revealed much higher mitochondrial membrane potential, motility and viability in the test group. In 2019 Buhling et al. carried out a meta-analysis [58] on two studies concerning selenium. The assessment showed significantly higher effect of selenium supplementation comparing to placebo on treating oligozoospermia (standard mean difference, SMD = 0,64) and asthenozoospermia (SMD = 1,39)

The influence of various selenium levels on female infertility remains uncertain and poorly researched at current moment. 


\section{Other trace elements impacting male fertility}

As far as the other micronutrients are concerned, there is a lack of studies showing the correlation between elevated levels and increase of spermatogenesis and sperm quality. In most cases, just their negative impact on those factors is contained.

\section{Iron}

It has been established repeatedly that elevated iron level is associated negatively with the spermatogenesis quality both in mice and men. What's more, in infertile men, seminal plasma iron levels are elevated $[59,60]$ However, iron deficiency seem to impair the spermatogenesis as well. For instance, in the studies referring to the results of men with iron deficiency anemia, there was a doubling of sperm count and all semen parameters after intravenous iron supplementation [61]. In addition, a significant role is observed in maintaining iron homeostasis for proper testicular function. As it turns out, ferroportin is expressed on Sertoli cells, which is present only on cells substantially involved in maintaining adequate serum iron levels $[62,63]$. Besides, it has been also established that there is a significant iron deposition in the testis of patients with transfusion-dependent beta-thalassemia and such findings might explain the high prevalence of impaired fertility in male patients, even though the pituitary function seems not to be decreased $[64,65]$.

\section{Manganese}

In humans, decreased sperm concentrations in men with the lowest and highest serum manganese concentrations suggest the necessity to maintain optimal levels of this micronutrient in order to keep the spermatogenesis working properly [66].

\section{Lead}

Despite the fact that, according to several trials, excessive lead environmental exposure has been associated with decreased sperm concentrations according to a few studies $[67,68,69,70]$ low-level lead exposure has been associated with higher testosterone levels [71]. Besides that, in some reports, there was no significant differences in $\mathrm{Pb}$ concentrations in abnormal or normozoospermic semen samples [72,73].

\section{Nickel}

As for nickel, its deficiency has been associated with the decrease in epididymal sperm counts in

rats

[74].

\section{Copper}

As far as the copper is concerned, there is a some kind of inconstancy in several trial's findings. Eidi et al. [75] and Yan Li et al. [76] reported a negative correlation between semen quality and $\mathrm{Cu}$ levels $(\mathrm{Cu}$ was considered as an environmental chemical pollutant for the workers of the industrial factory in the study of Li et al.), whilst in the study of Hashemi et al. [77], significantly lower levels of $\mathrm{Cu}$ was observed in the seminal fluid of asthenozoospermic subjects in comparison to normozoospermic men not exposed to poisonous amounts of $\mathrm{Cu}$. 
Meanwhile, in contrast, Aydemir et al. [60] showed higher levels of $\mathrm{Cu}$ in subfertile males compared to fertile ones. Undoubtedly, there is lack of unequivocal findings in available trials.

\section{Magnesium}

Seminal levels of $\mathrm{Mg}$ are often used for the assessment of premature ejaculation (PE) [78]. According to El Aaleba's et al. findings showed that PE patients had lower levels of seminal plasma Mg levels in comparison to healthy men alongside with similar results about the seminal levels of $\mathrm{Mg}$ levels in PE patients. Higher levels of $\mathrm{Mg}$ in normozoospermic males compared to asthenozoospermic males were observed in Hashemi's et al. results, which can be suspected to affect sperm motility [77].

\section{Cobalt}

Marzec-Wróblewska et al. found that increased Co concentration correlates with impaired semen and sperm motility and morphology of spermatozoa [72], similar findings have been represented in Kumar's et al. work [79], whereas the results of a study by Nikolaou et al. [80] and Guzikowski et al. [81] suggested that there is no adverse effect of Co ions on sperm parameters.

\section{Conclusion}

Summarizing, an impact of selected micronutrients on fertility is evident. Zinc regulates sperm motility, spermatogenesis, its low doses are necessary for germ cells. Zn deficiency are connected with apoptosis of Leydig cells and as a consequence lower testosterone production and an increase of LH and FSH level. Selenium has been found to influence testicular morphology, it is an antioxidant too. Lower level of Se may affects testosteron biosynthesis and causes some changes of the luteinizing hormone receptor. Iron has negative impact on fertility both in excessiveness and in deficiency - elevated iron level is associated with the worse spermatogenesis quality. Manganese, like iron, should be maintain in the relevant level to keep the spermatogenesis working properly. An interaction between Cooper and fertility has some uncertainty - most likely deficiency and excess is damaging. Magnesium affect sperm motility - its higher levels are observed in normozoospermic males compared to asthenozoospermic males. Cobalt has an impact on sperm motility and morphology of spermatozoa. 


\section{List of references}

1. Mascarenhas MN, Flaxman SR, Boerma T, Vanderpoel S, Stevens GA. National, regional, and global trends in infertility prevalence since 1990: a systematic analysis of 277 health surveys. PLoS Med. 2012;9(12):e1001356.

2. Zegers-Hochschild F, Adamson GD, de Mouzon J, Ishihara O, Mansour R, Nygren K, et al. The International Committee for Monitoring Assisted Reproductive Technology (ICMART) and the World Health Organization (WHO) Revised Glossary on ART Terminology, 2009. Hum Reprod. 2009 Nov 1;24(11):2683-7.

3. World Health Organization 2013."Sexual and reproductive health: Infertility definitions and terminology". Available http://www.who.int/reproductivehealth/topics/infertility/definitions/en/

4. Vander Borght M, Wyns C. Fertility and infertility: Definition and epidemiology. Clin Biochem. 2018 Dec;62:2-10.

5. Chowdhury SH, Cozma AI, Chowdhury JH. Infertility. Essentials for the Canadian Medical Licensing Exam: Review and Prep for MCCQE Part I. 2nd edition. Wolters Kluwer. Hong Kong. 2017.

6. Gabrielsen JS, Tanrikut C. Chronic exposures and male fertility: the impacts of environment, diet, and drug use on spermatogenesis. Andrology. 2016;4(4):648-61.

7. Leaver RB. Male infertility: an overview of causes and treatment options. Br J Nurs. 2016 Oct 13;25(18):S35-40.

8. Lindsay T.J., Vitrikas K.R. California. Am Fam Physician. 2015 Mar 1;91(5):308-314

9. $\quad$ R. S. Bedwal and A. Bahuguna, "Zinc, copper and selenium in reproduction," Experientia, vol. 50, no. 7, pp. 626-40, 1994.

10. M. I. Camejo, L. Abdala, G. Vivas-Acevedo, R. Lozano-Hernández, M. Angeli-Greaves, and E. D. Greaves, "Selenium, copper and zinc in seminal plasma of men with varicocele, relationship with seminal parameters," Biological trace element research, vol. 143, no. 3, pp. 1247-54, 2011.

11. A. I. S. B. Villaverde et al., "Blood and seminal plasma concentrations of selenium, zinc and testosterone and their relationship to sperm quality and testicular biometry in domestic cats," Animal reproduction science, vol. 150, no. 1-2, pp. 50-5, 2014.

12. K. Kerns, M. Zigo, and P. Sutovsky, "Zinc: A Necessary Ion for Mammalian Sperm Fertilization Competency," International journal of molecular sciences, vol. 19, no. 12, p. 4097, 2018.

13. T. P. Croxford, N. H. McCormick, and S. L. Kelleher, "Moderate zinc deficiency reduces testicular Zip6 and Zip10 abundance and impairs spermatogenesis in mice," The Journal of nutrition, vol. 141, no. 3, pp. 359-65, 2011.

14. M. B. Sørensen, M. Stoltenberg, K. Henriksén, E. Ernst, G. Danscher, and M. Parvinen, "Histochemical tracing of zinc ions in the rat testis," Molecular human reproduction, vol. 4, no. 5, pp. 423-8, 1998.

15. Q. CHU et al., "A potential role for zinc transporter 7 in testosterone synthesis in mouse Leydig tumor cells,” International Journal of Molecular Medicine, vol. 37, no. 6, pp. 1619-1626, Apr. 2016.

16. X. Zhang, T. Guan, B. Yang, Z. Chi, Z.-Y. Wang, and H. F. Gu, “A novel role for zinc transporter 8 in the facilitation of zinc accumulation and regulation of testosterone synthesis in Leydig cells of human and mouse testicles," Metabolism: clinical and experimental, vol. 88, pp. 40-50, 2018.

17. X. You et al., "Expression pattern of Zinc finger protein 185 in mouse testis and its role in regulation of testosterone secretion," Molecular medicine reports, vol. 16, no. 2, pp. 2101-2106, 2017.

18. M. Ishizuka et al., "Abnormal spermatogenesis and male infertility in testicular zinc finger protein Zfp318-knockout mice,” Development, growth \& differentiation, vol. 58, no. 7, pp. 600-8, 2016.

19. J. Zhao et al., "Zinc levels in seminal plasma and their correlation with male infertility: A systematic review and meta-analysis," Scientific reports, vol. 6, p. 22386, 2016.

20. J. J. Wirth and R. S. Mijal, "Adverse effects of low level heavy metal exposure on male reproductive function," Systems biology in reproductive medicine, vol. 56, no. 2, pp. 147-67, 2010.

21. A. M. Kabel, "Zinc/alogliptin combination attenuates testicular toxicity induced by doxorubicin in rats: Role of oxidative stress, apoptosis and TGF- $\beta 1 / \mathrm{NF}-\kappa \mathrm{B}$ signaling," Biomedicine \& Pharmacotherapy, vol. 97, pp. 439-449, Jan. 2018.

22. S. Loft, K. Vistisen, M. Ewertz, A. Tjønneland, K. Overvad, and H. E. Poulsen, "Oxidative DNA damage estimated by 8-hydroxydeoxyguanosine excretion in humans: influence of smoking, gender and body mass index," Carcinogenesis, vol. 13, no. 12, pp. 2241-2247, 1992. 
23. P. I. Oteiza, K. L. Olin, C. G. Fraga, and C. L. Keen, "Zinc deficiency causes oxidative damage to proteins, lipids and DNA in rat testes," The Journal of nutrition, vol. 125, no. 4, pp. 823-9, 1995.

24. S. Türk, R. Mändar, R. Mahlapuu, A. Viitak, M. Punab, and T. Kullisaar, "Male infertility: Decreased levels of selenium, zinc and antioxidants," Journal of Trace Elements in Medicine and Biology, vol. 28, no. 2, pp. 179-185, Apr. 2014.

25. A. Wdowiak, G. Bakalczuk, and S. Bakalczuk, "Evaluation of effect of selected trace elements on dynamics of sperm DNA fragmentation," Postepy higieny i medycyny doswiadczalnej (Online), vol. 69, pp. 1405-10, 2015.

26. M. I. Camejo, L. Abdala, G. Vivas-Acevedo, R. Lozano-Hernández, M. Angeli-Greaves, and E. D. Greaves, "Selenium, copper and zinc in seminal plasma of men with varicocele, relationship with seminal parameters," Biological trace element research, vol. 143, no. 3, pp. 1247-54, 2011.

27. A. R. S. Alsalman, L. A. Almashhedy, and M. H. Hadwan, "Effect of Oral Zinc Supplementation on the Thiol Oxido-Reductive Index and Thiol-Related Enzymes in Seminal Plasma and Spermatozoa of Iraqi Asthenospermic Patients," Biological Trace Element Research, vol. 184, no. 2, pp. 340-349, Dec. 2017.

28. T. Ajina, A. Sallem, Z. Haouas, and M. Mehdi, "Total antioxidant status and lipid peroxidation with and without in vitro zinc supplementation in infertile men," Andrologia, vol. 49, no. 7, p. e12703, Sep. 2016.

29. Y.-L. Liu et al., "The effectiveness of zinc supplementation in men with isolated hypogonadotropic hypogonadism," Asian journal of andrology, vol. 19, no. 3, pp. 280-285, 2017.

30. M. Raigani et al., "The micronutrient supplements, zinc sulphate and folic acid, did not ameliorate sperm functional parameters in oligoasthenoteratozoospermic men," Andrologia, vol. 46, no. 9, pp. 956-62, 2014.

31. A. Taravati and F. Tohidi, "Association between seminal plasma zinc level and asthenozoospermia: a meta-analysis study," Andrologia, vol. 48, no. 6, pp. 646-653, Nov. 2015.

32. J. Sun et al., "Heavy Metal Level in Human Semen with Different Fertility: a MetaAnalysis," Biological Trace Element Research, vol. 176, no. 1, pp. 27-36, Jul. 2016.

33. K. Buhling, A. Schumacher, C. Z. Eulenburg, and E. Laakmann, "Influence of oral vitamin and mineral supplementation on male infertility: a meta-analysis and systematic review," Reproductive biomedicine online, vol. 39, no. 2, pp. 269-279, 2019.

34. M. K. Hedaoo, K. P. Khllare, M. D. Meshram, S. K. Sahatpure, and M. G. Patil, 'Study of some serum trace minerals in cyclic and non-cyclic surti buffaloes', Vet. World, p. 2, 2008.

35. L. Flohe, W. A. Günzler, and H. H. Schock, 'Glutathione peroxidase: A selenoenzyme', FEBS Lett., vol. 32, no. 1, pp. 132-134, May 1973.

36. A. Noblanc et al., 'Glutathione peroxidases at work on epididymal spermatozoa: an example of the dual effect of reactive oxygen species on mammalian male fertilizing ability', J. Androl., vol. 32, no. 6, pp. 641-650, Dec. 2011.

37. E. Chabory et al., 'Epididymis seleno-independent glutathione peroxidase 5 maintains sperm DNA integrity in mice', J. Clin. Invest., vol. 119, no. 7, pp. 2074-2085, Jul. 2009.

38. M. Maiorino, M. Scapin, F. Ursini, M. Biasolo, V. Bosello, and L. Flohé, 'Distinct promoters determine alternative transcription of gpx-4 into phospholipid-hydroperoxide glutathione peroxidase variants', J. Biol. Chem., vol. 278, no. 36, pp. 34286-34290, Sep. 2003.

39. H. Imai et al., 'Depletion of selenoprotein GPx4 in spermatocytes causes male infertility in mice', $J$. Biol. Chem., vol. 284, no. 47, pp. 32522-32532, Nov. 2009.

40. L. Flohé, 'Selenium in mammalian spermiogenesis', Biol. Chem., vol. 388, no. 10, Jan. 2007.

41. A. Agarwal and S. S. R. Allamaneni, 'Free radicals and male reproduction', J. Indian Med. Assoc., vol. 109, no. 3, pp. 184-187, Mar. 2011.

42. D. Behne, H. Weiler, and A. Kyriakopoulos, 'Effects of selenium deficiency on testicular morphology and function in rats', J. Reprod. Fertil., vol. 106, no. 2, pp. 291-297, Mar. 1996.

43. R. Kaur and K. Kaur, 'Effects of dietary selenium (SE) on morphology of testis and cauda epididymis in rats', Indian J. Physiol. Pharmacol., vol. 44, no. 3, pp. 265-272, Jul. 2000.

44. G. E. Olson, V. P. Winfrey, S. K. Nagdas, K. E. Hill, and R. F. Burk, 'Selenoprotein P is required for mouse sperm development', Biol. Reprod., vol. 73, no. 1, pp. 201-211, Jul. 2005. 
45. G. E. Olson, V. P. Winfrey, S. K. Nagdas, K. E. Hill, and R. F. Burk, 'Apolipoprotein E receptor-2 (ApoER2) mediates selenium uptake from selenoprotein P by the mouse testis', J. Biol. Chem., vol. 282, no. 16, pp. 12290-12297, Apr. 2007.

46. M. Conrad et al., 'The nuclear form of phospholipid hydroperoxide glutathione peroxidase is a protein thiol peroxidase contributing to sperm chromatin stability', Mol. Cell. Biol., vol. 25, no. 17, pp. 7637-7644, Sep. 2005 .

47. H. Imai et al., 'Early embryonic lethality caused by targeted disruption of the mouse PHGPx gene', Biochem. Biophys. Res. Commun., vol. 305, no. 2, pp. 278-286, May 2003.

48. D. Behne, T. Höfer, R. von Berswordt-Wallrabe, and W. Elger, 'Selenium in the testis of the rat: studies on its regulation and its importance for the organism', J. Nutr., vol. 112, no. 9, pp. 1682-1687, Sep. 1982.

49. D. Behne, M. Duk, and W. Elger, 'Selenium content and glutathione peroxidase activity in the testis of the maturing rat', J. Nutr., vol. 116, no. 8, pp. 1442-1447, Aug. 1986.

50. R. S. Bedwal and A. Bahuguna, 'Zinc, copper and selenium in reproduction', Experientia, vol. 50, no. 7, pp. 626-640, Jul. 1994.

51. M. I. Camejo, L. Abdala, G. Vivas-Acevedo, R. Lozano-Hernández, M. Angeli-Greaves, and E. D. Greaves, 'Selenium, copper and zinc in seminal plasma of men with varicocele, relationship with seminal parameters', Biol. Trace Elem. Res., vol. 143, no. 3, pp. 1247-1254, Dec. 2011.

52. A. Ardestani Zadeh, D. Arab, N. S. Kia, S. Heshmati, and S. N. Amirkhalili, 'The role of Vitamin E Selenium - Folic Acid Supplementation in Improving Sperm Parameters After Varicocelectomy: A Randomized Clinical Trial', Urol. J., vol. 16, no. 5, pp. 495-500, Oct. 2019.

53. B. Pajovic, A. Dimitrovski, N. Radojevic, and M. Vukovic, 'A correlation between selenium and carnitine levels with hypo-osmotic swelling test for sperm membrane in low-grade varicocele patients', Eur. Rev. Med. Pharmacol. Sci., vol. 20, no. 4, pp. 598-604, 2016.

54. M. Eroglu et al., 'Blood serum and seminal plasma selenium, total antioxidant capacity and coenzyme q10 levels in relation to semen parameters in men with idiopathic infertility', Biol. Trace Elem. Res., vol. 159, no. 1-3, pp. 46-51, Jun. 2014.

55. A. Chinyere Nsonwu-Anyanwu et al., 'Heavy metals, biomarkers of oxidative stress and changes in sperm function: A case-control study’, Int. J. Reprod. Biomed. Yazd Iran, vol. 17, no. 3, Mar. 2019.

56. U. Marzec-Wróblewska et al., 'The employment of IVF techniques for establishment of sodium, copper and selenium impact upon human sperm quality', Reprod. Fertil. Dev., Mar. 2015.

57. A. A. Ghafarizadeh, G. Vaezi, M. A. Shariatzadeh, and A. A. Malekirad, 'Effect of in vitro selenium supplementation on sperm quality in asthenoteratozoospermic men', Andrologia, vol. 50, no. 2, Mar. 2018.

58. K. Buhling, A. Schumacher, C. zu Eulenburg, and E. Laakmann, 'Influence of oral vitamin and mineral supplementation on male infertility: a meta-analysis and systematic review', Reprod. Biomed. Online, vol. 39, no. 2, pp. 269-279, Aug. 2019.

59. Lourdes de Pereira M, Garcia e Costa F. Spermatogenesis recovery in the mouse after iron injury. Hum Exp Toxicol 22 (2003), pp. 275-279

60. Aydemir B, Kiziler AR, Onaran I, Alici B, Ozkara H \& Akyolcu MC. Impact of $\mathrm{Cu}$ and $\mathrm{Fe}$ concentrations on oxidative damage in male infertility. Biol Trace Elem Res 112 (2006), pp. 193-203.

61. Soliman A, Yassin M, De Sanctis V. Intravenous iron replacement therapy in eugonadal males with iron-deficiency anemia: effects on pituitary gonadal axis and sperm parameters; A pilot study. Indian J Endocrinol Metab 18 (2014), pp. 310-316

62. Leichtmann-Bardoogo Y, Cohen LA, Weiss A, Marohn B, Schubert S, Meinhardt A \& Meyron-Holtz EG. Compartmentalization and regulation of iron metabolism proteins protect male germ cells from iron overload. Am J Physiol Endocrinol Metab 302 (2012), E1519-E1530.

63. Griffin KP, Ward DT, Liu W, Stewart G, Morris ID, Smith CP. Differential expression of divalent metal transporter DMT1 (Slc11a2) in the spermatogenic epithelium of the developing and adult rat testis. Am J Physiol Cell Physiol 288 (2005), C176-C184

64. Chen M, Peng S, Lu M et al. Effect of iron overload on impaired fertility in male patients with transfusion-dependent beta-thalassemia. Pediatr Res 83 (2018), pp. 655-661

65. De Sanctis V, Soliman AT, Elsedfy H, Di Maio S, Canatan D, Soliman N, Karimi M, Kattamis C. Gonadal dysfunction in adult male patients with thalassemia major: an update for clinicians caring for thalassemia, Expert Review of Hematology, 10:12 (2017), pp. 1095-1106 
66. Wirth JJ, Rossano MG, Daly DC, Paneth N, Puscheck E, Potter RC, Diamond MP. Ambient manganese exposure is negatively associated with human sperm motility and concentration. Epidemiology 18 (2007), pp. $270-273$

67. Benoff S, Centola GM, Millan C, Napolitano B, Marmar JL, Hurley IR. Increased seminal plasma lead levels adversely affect the fertility potential of sperm in IVF. Hum Reprod 18 (2003), pp. 374-383

68. Pant N, Upadhyay G, Pandey S, Mathur N, Saxena DK, Srivastava SP. Lead and cadmium concentration in the seminal plasma of men in the general population: correlation with sperm quality. Reprod Toxicol 17 (2003), pp. 447-450

69. Pant N, Kumar G, Upadhyay AD, Gupta YK, Chaturvedi PK. Correlation between lead and cadmium concentration and semen quality. Andrologia 44 (2014), pp. 370-375.

70. Li P, Zhong Y, Jiang X, Wang C, Zuo Z, Sha A. Seminal plasma metals concentration with respect to semen quality. Biol Trace Elem Res 148 (2012), pp. 1-6

71. Telisman S, Colak B, Pizent A, Jurasovic J, Cvitkovic P. Reproductive toxicity of low-level lead exposure in men. Environ Res 105 (2007),pp. 256-266.

72. Marzec-Wróblewska U, Kamiński P, Łakota P et al. Human Sperm Characteristics with Regard to Cobalt, Chromium, and Lead in Semen and Activity of Catalase in Seminal Plasma. Biol Trace Elem Res 188 (2019), pp. 251-260

73. Xu DX, Shen HM, Zhu QX, Chua L, Wang QN, Chia SE, Ong CN. The associations among semen quality, oxidative DNA damage in human spermatozoa and concentrations of cadmium, lead and selenium in seminal plasma. Mutat Res (2003) 534(1-2), pp. 155-163

74. Yokoi K, Uthus EO, Nielsen FH. Nickel deficiency diminishes sperm quantity and movement in rats. Biol Trace Elem Res 93, (2003), pp. 141-154

75. Eidi M, Eidi A, Pouyan O, Shahmohammadi P, Fazaeli R, Bahar M. Seminal plasma levels of copper and its relationship with seminal parameters. Iran J Reprod Med. 2010; 8(2): 60-5. 17.

76. Yan L, Qiaoyan G, Mingcai L, Mengyang L, Xueming G. Cadmium, Chromium, and Copper Concentration plus Semen-Quality in Environmental Pollution Site, China. Iran J Public Health. 2014; 43(1): pp. $35-41$.

77. Hashemi MM, Behnampour N, Nejabat M, Tabandeh A, Ghazi-Moghaddam B, Joshaghani HR.Â Impact of Seminal Plasma Trace Elements on Human Sperm Motility Parameters. Rom J Intern Med. 2018 Mar 1;56(1):15-20

78. El Aaleba, Abdo Hm, Elshahed Ar, Bayoumi Im, Hamdy Mhm. Measuement of seminal and serum plasma magnesium levels in premature ejaculation. The Gulf Journal of Dermatology and Venereology (GJDV). 2012; 20(2): 35-9

79. Kumar GP, Laloraya M, Laloraya MM Powerful anti-sperm motility action of cobaltous ion and its recovery by a sulfhydryl compound. Contraception (1999) 41(6), pp. 633-639

80. Nikolaou VS, Petit A, Zukor DJ, Papanastasiou C, Huk OL, Antoniou J Presence of cobalt and chromium ions in the seminal fluid of young patients with metal-on-metal total hip arthroplasty. J Arthroplast 28(1) (2013), pp. 161-167

81. Guzikowski W, Szynkowska MI, Motak-Pochrzęst H, Pawlaczyk A, Sypniewski S Trace elements in seminal plasma of men from infertile couples. Arch. Med Sci 19 11(3) (2015), pp. 591-598 